\title{
Pengaruh Kualitas Produk, Harga, Dan Kualitas Pelayanan Terhadap Kepuasan Konsumen Pada Rumah Makan Dabu-Dabu Iris Fresh Wenang Manado
}

\author{
Gahensya Keloay \\ Wehelmina Rumawas \\ Sandra Asaloei
}

\begin{abstract}
Jurusan Ilmu Administrasi Bisnis, Program Studi Administrasi Bisnis
Fakultas Ilmu Sosial dan Politik, Universitas Sam Ratulangi

gahensya_keloay@yahoo.com
\end{abstract}

\begin{abstract}
This research was conducted in Dabu-Dabu Iris Fresh Restaurant, Wenang Manado, which aims to find out the 1) effect of product quality ;2) price and ; 3) service quality on customer satisfaction in Dabu-Dabu Iris Fresh Restaurant, Manado, both individually and in groups. With the focus of the problem is whether product quality, price and service quality affect consumer satisfaction in Rumah Makan Dabu-Dabu Iris Fresh, Wenang Manado. the method used in this study uses quantitative descriptive methods and The population that came in the Dabu-Dabu Iris Fresh Restaurant, Manado Heritage is unknown, therefore the researcher took a sample of 50 respondents using a purposive sampling technique that is consideration of populations that are easily found and this research will only be given to visitors who have visited the House. Eating Dabu-Dabu Iris Fresh, Managing Manado at least 5 times, and the research method used is quantitative descriptive method. The analytical tool used in the data instrument test (validity and reliability test), classic assumption test (normality test, multicollinearity test and heteroscedasticity test), data analysis (multiple regression analysis, test $t, F$ test and test coefficient of determination R2). Based on the t test obtained states that product quality has an influence on customer satisfaction individually. While price is the determination of the value of a product in the minds of consumers that must be paid by consumers to obtain a product of Dabu-Dabu Iris Fresh Restaurant, Wenang Manado. The service quality provided by Dabu-Dabu Iris Fresh Restaurant, Wenang Manado affects consumer satisfaction.
\end{abstract}

Key Words : Quality Of Product, Price, Quality Of Service

\section{Pendahuluan}

Kualitas produk merupakan suatu kondisi yang sangat penting yang berhubungan dengan produk yang memenuhi atau melebihi harapan konsumen. Produk ditawarkan atau diproduksi dalam pasaran agar supaya bisa menarik perhatian dari konsumen, sehingga konsumen akan tertarik untuk membeli maupun mengkonsumsi produk tersebut untuk memenuhi kebutuhan dan keinginannya.

Harga merupakan penentuan nilai suatu produk. Semakin ekonomis harga yang ditawarkan, ditambah dengan kualitas produk yang memuaskan maka konsumen 
akan semakin tertarik dan merasa puas sehingga konsumen ingin mengunjungi kembali tempat tersebut. Begitu juga sebaliknya, jika menurut konsumen harga yang tidak ditawarkan terlalu mahal dan rasanya tidak sesuai dengan apa yang diharapkan, maka konsumen tidak akan mengunjungi kembali tempat tersebut. Untuk itulah faktor harga menentukan tingkat kepuasan konsumen yang berkunjung, karena konsumen juga melakukan perbandingan harga dengan lokasi lain.

Kualitas pelayanan mempengaruhi kepuasan konsumen, kualitas pelayanan merupakan ciri atau sifat yang memiliki pengaruh untuk memuaskan kebutuhan yang dinyatakan. Produsen akan memiliki kualitas dalam rumah makan, jika pelayanan yang diberikan memenuhi atau melebihi dari harapan konsumen. Jika karyawan memberikan pelayanan dengan baik kepada konsumen, maka konsumen akan merasa nyaman sehingga kepuasan konsumen akan lebih meningkat.

Menurut Lovelock dan Wirtz (2011) kepuasan adalah suatu sikap yang diputuskan berdasarkan pengalaman yang didapatkan kepuasan merupakan penilaian mengenai ciri atau keistimewaan produk atau jasa atau produk itu sendiri yang menyediakan tingkat kesenangan konsumen berkaitan dengan pemenuhan kebutuhan konsumsi konsumen.
Mc Charty dan Perreault (2010) mengemukakan bahwa, "Produk merupakan hasil dari produksi yang akan dilempar kepada konsumen untuk didistribusikan dan dimanfaatkan konsumen untuk memenuhi kebutuhannya". Kotler dan Amstrong (dalam Lapalelo B. 2015) mengatakan bahwa "Harga adalah jumlah uang yang dibebankan untuk sebuah produk atau jasa". Lebih luas lagi, harga adalah jumlah nilai yang konsumen pertukaran untuk mendapatkan manfaat dari memiliki atau menggunakan produk atau jasa”.

Gaol (dalam R. Wehelmina 2018) mengemukakan pricing jobs meliputi dua kegiatan yaitu menetapkan level pembayaran yang tepat untuk setiap jabatan dan mengelompokkan level pembayaran yang berbeda itu kedalam suatu struktur yang dikelola secara efektif. 1) Level Pembayaran (Pay Level) yang tepat untuk jabatan mencerminkan nilai yang relative dan nilai mutlak dari jabatan yang bersangkutan ; 2) Struktur Kompensasi analisis kompensasi merasa lebih mudah untuk menyatukan jabatan-jabatan ke dalam kelas jabatan (job classes). Semua jabatan yang berada didalam kelas yang sama memperoleh gaji yang sama.

Menurut Goetsh dan Davis dalam Tjiptono mengatakan kualitas merupakan suatu kondisi dinamis yang berhubungan dengan produk, jasa, manusia, proses dan lingkungan yang memenuhi atau melebihi 
harapan. Kualitas pelayanan adalah penilaian konsumen tentang keandalan dan superioritas pelayanan secara keseluruhan. Konsumen akan membuat perbandingan antara yang mereka berikan dengan apa yang didapat.

Menurut Zeithhaml, Parasuraman \& Berry (dalam Hardiansyah 2011:) untuk mengetahui kualitas pelayanan yang dirasakan secara nyata oleh konsumen, ada indikator kualitas pelayanan yang terletak pada lima dimensi kualitas pelayanan, yaitu: 1) Tangibles (berwujud) kualitas pelayanan berupa sarana fisik perkantoran, komputerisasi administrasi, ruang tunggu, tempat informasi ; 2) Reliability (kehandalan) : kemampuan dan keandalan untuk menyediakan pelayanan yang terpercaya ; 3) Responsiveness (ketanggapan) : kesanggupan untuk membantu dan menyediakan pelayanan secara cepat dan tepat, serta tanggap terhadap keinginan konsumen ; 4) Assurance (jaminan) : kemampuan dan keramahan serta sopan santun pegawai dalam meyakinkan kepercayaan konsumen ; 5) Emphaty (Empati) : sikap tegas tetapi penuh perhatian dari pegawai terhadap konsumen.

\section{Metode Penelitian}

Penelitian ini bertujuan untuk menguji pengaruh kualitas produk, harga, dan kualitas pelayanan terhadap kepuasan konsumen. Sesuai dengan perumusan masalah dan tujuan penelitian yang hendak dicapai, maka penelitian ini mengunakan jenis penelitian deskriptif kuantitatif. Menurut Sugiyono (2012) metode penelitian kuantitatif berlandaskan pada filsafat positivism, digunakan untuk meneliti pada populasi atau sampel tertentu, pengumpulan data menggunakan instrument penelitian, analisis data bersifat kuantitatif/statistic, dengan tujuan untuk menguji hipotesis yang telah ditetapkan.

Populasi yang dimaksud dalam penelitian ini adalah seluruh konsumen yang mengunjungi Rumah Makan DabuDabu Iris Fresh, Wenang Manado, dan jumlah populasi dari Rumah Makan DabuDabu Iris Fresh, Wenang Manado jumlahnya tidak diketahui dikarenakan konsumen yang datang tidak menentu, oleh karena itu populasinya tidak diketahui. Sampel yang digunakan dalam penelitian ini berjumlah 50 responden. Untuk menentukan sampel yang akan digunakan dalam penelitian, digunakan teknik purposive sampling yaitu teknik penentuan sampel dengan pertimbangan tertentu dan tidak perlu menggunakan rumus. Dan pertimbangan tertentu yang dimaksud yaitu pertimbangan bagi konsumen yang melakukan transaksi minimal 5 kali di Rumah Makan Dabu-Dabu Iris Fresh, Wenang Manado dan mudah ditemui.

Dalam penelitian ini digunakan daftar pernyataan (kuesioner) yang disusun berdasarkan model Likert dengan lima 
pilihan jawaban dengan rentang nilai antara 1 sampai 5 untuk menjaring data primer dari kalangan responden mengenai Kualitas Produk, Harga dan Kualitas Pelayanan Terhadap Kepuasan Konsumen.

Data yang dikumpulkan dalam penelitian ini ada 2 jenis yaitu 1) Data primer, yaitu data yang diperoleh langsung dari penyebaran kuesioner kepada responden. 2) Data sekunder yaitu data pendukung yang berupa dokumendokumen dan hasil observasi yang diperoleh dari penelitian.

Data yang telah dijaring dengan kuesioner diberi nilai dan ditabulasikan untuk selanjutnya dianalisis jawaban yang diperoleh dari responden sesuai dengan nilai variabel yang telah ditetapkan selanjutnya akan dianalisis dengan menggunakan software SPSS versi 22.00, dimana teknik analisis data ini dilakukan untuk mengetahui pengaruh dengan pendekatan anlisis linier.

\section{Hasil Penelitian}

Analisis Pengaruh (Uji F)

Tabel 1. Hasil Analisis Uji F

\begin{tabular}{cccc}
\hline$F_{\text {hitung }}$ & $F_{\text {tabel }}$ & Sig. & Keterangan \\
\hline 13.546 & 2.806 & 0.000 & Ada \\
& & & pengaruh \\
& & & simultan
\end{tabular}

Sumber : Diolah SPSS Versi 22.00

Uji F dilakukan untuk mengetahui apakah model regresi linier dengan variabel kualitas produk (X1), harga (X2), kualitas pelayanan (X3) memiliki pengaruh terhadap kepuasan konsumen (Y).

Dari hasil uji F (Anova) pada tabel 1 dapat dilihat hasil yang diperoleh adalah nilai $\mathrm{F}_{\text {hitung }}=13.546$ derajat bebas $(3,49)$ dengan nilai $\mathrm{a}=0,05$ adalah 2.806. Dengan demikian $\mathrm{F}_{\text {hitung }}>\mathrm{F}_{\text {tabel }}$ atau $13.546>2.806$ dengan tingkat probabilitas sig. 0.000. oleh karena itu 0.000 jauh lebih kecil dari 0,05.

Berdasarkan kriteria pengujian hipotesis maka Ho ditolak dan Ha diterima, ini berarti model regresi dapat dipakai untuk pengukuran pengaruh atau peramalan.

Pengaruh variabel kualitas produk (X1), harga (X2), dan kualitas pelayanan (X3) terhadap kepuasan konsumen (Y) dapat diketahui dari koefisien determinasi (Rsquare) pada table 2 berikut ini.

Table 2. Koefisien Determinasi $\left(\mathrm{R}^{2}\right)$

\begin{tabular}{ccc}
\hline $\mathrm{R}$ & $\mathrm{R}^{2}$ & Keterangan \\
\hline 0.885 & 0.669 & $\begin{array}{c}\text { Presentase } \\
\text { pengaruh } 66,9 \%\end{array}$ \\
& & \\
\hline
\end{tabular}

Dari data pada tabel 2 diperoleh nilai koefisien determinasi $\left(\mathrm{R}^{2}\right)$ sebesar 0.669, hal ini berarti bahwa variabel independen dalam model (variabel kualitas produk, variabel harga, dan variabel kualitas pelayanan) menjelaskan variasi kepuasan konsumen di Rumah Makan Dabu-Dabu Iris Fresh, Wenang Manado sebesar $66,9 \%$ dan $33.1 \%$ dijelaskan oleh factor atau variabel lain yang ada diluar model. 
Tabel 3. Regresi Linier Berganda

\begin{tabular}{lc}
\hline Variabel & $\begin{array}{c}\text { Unstandardized } \\
\text { Coefficients }\end{array}$ \\
\hline (Constant) & 4.003 \\
Kualitas & 0.314 \\
Produk & 0.519 \\
Harga & 0.104 \\
Kualitas & \\
Pelayanan & \\
\hline
\end{tabular}

Dari data pada tabel diatas variabel kualitas produk (X1) 0.314, harga (X2) 0.519) dan kualitas (X3) 0.104) dengan konstanta 4.003 maka diperoleh persamaan perhitungan regresi yaitu : $\mathrm{Y}=4.003+$ $0.314+0.519+-.104$.

\section{Pembahasan}

Berdasarkan dari hasil analisis yang sudah dijelaskan diatas, dapat dikatakan bahwa variabel kualitas produk, variabel harga, variabel kualitas pelayanan mempunyai pengaruh positif dan signifikan terhadap kepuasan konsumen di Rumah Makan Dabu-Dabu Iris Fresh, Wenang Manado.

Dari penelitian ini menunjukkan bahwa kualitas produk di Rumah Makan Dabu-Dabu Iris Fresh, Wenang Manado mempengaruhi terhadap kepuasan konsumen, dengan ketersediaan kualitas produk yang beraneka ragam jenis ditawarkan ke konsumen, sehingga konsumen tertarik untuk membeli atau mengonsumsi untuk memenuhi keinginan dan kebutuhannya.

Harga merupakan penentuan nilai suatu produk di benak konsumen yang harus dibayar oleh konsumen untuk memperoleh produk Rumah Makan DabuDabu Iris Fresh, Wenang Manado. Semakin terjangkau harganya, maka konsumen akan melakukan pembelian ke Rumah Makan Dabu-Dabu Iris Fresh, Wenang Manado.

Kualitas pelayanan yang diberikan di Rumah Makan Dabu-Dabu Iris Fresh, Wenang Manado mempengaruhi kepuasan konsumen, karena kualitas pelayanan yang diberikan di dalam Rumah Makan DabuDabu Iris Fresh, Wenang Manado ini sangat baik sehingga kepuasan konsumen terpenuhi. Kualitas pelayanan ini juga merupakan ciri serta sifat dari suatu pelayanan yang berpengaruh pada kemampuan untuk memuaskan cirri sifat suatu pelayanan yang berpengaruh pada kemampuan untuk memuaskan kebutuhan yang dinyatakan atau yang tersirat. Seorang produsen dapat memberikan kualitas bila pelayanan yang diberikan dapat memenuhi atau melebihi harapan konsumen.

Dan dari ketiga variabel diatas (variabel kualitas produk, variabel harga, dan variabel kualitas pelayanan) variabel yang paling mempengaruhi kepuasan konsumen dilihat dari hasil perhitungan SPSS adalah variabel harga. Yang berarti harga sangat memiliki pengaruh yang kuat terhadap kepuasan konsumen di Rumah 
Makan Dabu-Dabu Iris Fresh, Wenang Manado. Dan dari hasil observasi juga menyatakan bahwa hampir seluruh konsumen setuju dengan harga yang di terapkan di dalam menu-menu makanan karena tingkat keterjangkauan harga sangat baik ditambah juga dengan kualitas produk yang baik dan kualitas pelayanan yang diberikan sangat mendukung.

Berdasarkan dari hasil penelitian ini menunjukkan bahwa penelitian ini memiliki konsisten / kesamaan penelitian dengan Nanik (2015) yang memiliki kesamaan dalam jumlah sampel yaitu keduanya memiliki 50 sampel atau 50 responden. Dan menghasilkan hasil yang konsisten / kesamaan bahwa kualitas produk, harga dan kualitas pelayanan berpengaruh positif terhadap kepuasan konsumen.

Begitu juga adanya kesamaan dengan penelitian terdahulu Anindya (2017) yang menghasilkan bahwa kualitas produk, kualitas layanan, dan nilai pelanggan berpengaruh positif dan signifikan terhadap kepuasan konsumen dan minat beli pada Blend S Pasta \& Chocolate.

Dan memiliki kesamaan juga dengan hasil penelitian dari Liyundira (2017) yang menghasilkan store layout, harga, lokasi, promosi berpengaruh positif terhadap kepuasan konsumen di Rocket Chicken.

\section{Kesimpulan}

Berdasarkan dari hasil analisis yang sudah dijelaskan diatas, dapat dikatakan bahwa variabel kualitas produk, variabel harga, variabel kualitas pelayanan mempunyai pengaruh positif dan signifikan terhadap kepuasan konsumen di Rumah Makan Dabu-Dabu Iris Fresh, Wenang Manado.

Dari hasil penelitian diatas dapat diketahui bahwa harga memiliki pengaruh yang paling kuat terhadap kepuasan konsumen di Rumah Makan Dabu-Dabu Iris Fresh, Wenang Manado dibandingkan dengan variabel kualitas produk dan variabel kualitas pelayanan. Dan dari hasil observasi juga menyatakan bahwa hampir seluruh konsumen setuju dengan harga yang di terapkan di dalam menu-menu makanan karena tingkat keterjangkauan harga sangat baik ditambah juga dengan kualitas produk yang baik dan kualitas pelayanan yang diberikan sangat mendukung.

Dari hasil penelitian diatas diketahui bahwa peneliti hanya meneliti kualitas produk, harga, dan kualitas pelayanan sehingga dalam penelitian ini hanya dapat memberikan informasi sebesar pengaruh ketiga faktor tersebut terhadap kepuasan konsumen Rumah Makan DabuDabu Iris Fresh, Wenang Manado. 


\section{Saran}

Dari hasil penelitian ini dapat diketahui bahwa kualitas produk, harga dan kualitas pelayanan memiliki pengaruh positif pada kepuasan konsumen Rumah Makan Dabu-Dabu Iris Fresh, Wenang Manado. Oleh karena itu kualitas yang ada di rumah makan ini harus selalu dipertahankan dan di tingkatkan lagi agar para konsumen akan kembali membeli di rumah makan dan menjadi loyal atau pelanggan tetap di Rumah Makan DabuDabu Iris Fresh, Wenang Manado.

Dapat diketahui juga bahwa konsumen sangat puas dengan harga di Rumah Makan Dabu-Dabu Iris Fresh, Wenang Manado. Oleh karena itu, diharapkan bagi rumah makan untuk mempertahankan setiap prestasi yang dicapai oleh rumah makan demi menghindari adanya keluhan dari konsumen.

Bagi peneliti yang akan melakukan penelitian selanjutnya, sebaiknya peneliti harus menambahkan variabel lain yang belum tercantum dalam penelitian ini karena masih terdapat faktor-faktor lain yang dapat mempengaruhi kepuasan konsumen sehingga bisa memperoleh model statistik yang baik

\section{Daftar Pustaka}

Anindya (2017) Faktor-Faktor Yang Mempengaruhi Kepuasan Konsumen Serta Dampaknya Terhadap Minat Beli Ulang Konsumen
Pada Blend S Pasta \& Chocolate Cabang UNIKA Semarang.

Gaol, L. Jimmy. 2014. A to Z Human Capital Manajemen Sumber Daya Manusia. PT. Grasindo, Jakarta.

Hardiansyah. 2011. Kualitas Pelayanan Publik, Yogyakarta: Gaya Media.

Kotler, Philip dan Gary, Armstrong. 2001. Prinsip-prinsip Pemasaran. Alih Bahasa Iman Nurmawan Jakarta: Erlangga.

Lapalelo, B. Pio, R. J. Tampi. J. R. E. 2015. Pengaruh Sistem Informasi Pemasaran dan Kualitas Pelayanan terhadap Kepuasan Pelanggan dan Loyalitas Pelanggan. Jurnal Administrasi Publik. Vol 1. No 028.

Liyundira. 2017 Faktor-Faktor Yang Mempengaruhi Kepuasan Konsumen Di Rocket Chicken Purbalingga

Mc Carthy dan Perreault, 2003. DasarDasar Pemasaran. Alih Bahasa Agus Dharma. Jakarta: Erlangga

Nanik (2015) Faktor-Faktor Yang Mempengaruhi Kepuasan Konsumen Pada Rumah Makan Special Sambal Di Jl. Blewah, Karangasem, Surakarta.

Rumawas W. 2015. Pengaruh Kepemimpinan Terhadap Kepuasan Kerja Karyawan. Jurnal Administrasi Publik. Vol. 4. No 35 .

Sugiyono. 2011. Metode Penelitian Kuantitatif, Kualitatif, dan $R \& D$. Bandung: AFABETA, CV. 
Swastha, Basu. 2000. Azas-Azas Marketing.

Liberty. Yogyakarta.

Tjiptono, Fandy. 2001. Strategi Pemasaran.

Edisi Kedua. Cetakan Keenam.

Yogyakarta: Penerbit. Andy. 